\title{
BMJ Open Effect of two additional interventions, test and reflection, added to standard cardiopulmonary resuscitation training on seventh grade students' practical skills and willingness to act: a cluster randomised trial
}

Anette Nord, ${ }^{1}$ Håkan Hult, ${ }^{2}$ Susanne Kreitz-Sandberg, ${ }^{3}$ Johan Herlitz, ${ }^{4}$ Leif Svensson, ${ }^{5}$ Lennart Nilsson ${ }^{1}$

To cite: Nord A, Hult H, KreitzSandberg S, et al. Effect of two additional interventions, test and reflection, added to standard cardiopulmonary resuscitation training on seventh grade students' practical skills and willingness to act: a cluster randomised trial. BMJ Open 2017;7:e014230. doi:10.1136/ bmjopen-2016-014230

- Prepublication history and additional material for this paper are available online. To view these files please visit the journal online (http://dx.doi. org/10.1136/bmjopen-2016014230).

Received 9 September 2016 Revised 6 February 2017 Accepted 3 March 2017

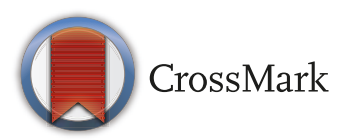

For numbered affiliations see end of article.

Correspondence to Dr Lennart Nilsson; lennart.nilsson@liu.se

\section{ABSTRACT}

Objectives The aim of this research is to investigate if two additional interventions, test and reflection, after standard cardiopulmonary resuscitation (CPR) training facilitate learning by comparing 13-year-old students' practical skills and willingness to act.

Settings Seventh grade students in council schools of two municipalities in south-east Sweden.

Design School classes were randomised to CPR training only (0), CPR training with a practical test including feedback (T) or CPR training with reflection and a practical test including feedback (RT). Measures of practical skills and willingness to act in a potential lifethreatening situation were studied directly after training and at 6 months using a digital reporting system and a survey. A modified Cardiff test was used to register the practical skills, where scores in each of 12 items resulted in a total score of 12-48 points. The study was conducted in accordance with current European Resuscitation Council guidelines during December 2013 to October 2014.

Participants 29 classes for a total of 587 seventh grade students were included in the study.

Primary and secondary outcome measures The total score of the modified Cardiff test at 6 months was the primary outcome. Secondary outcomes were the total score directly after training, the 12 individual items of the modified Cardiff test and willingness to act.

Results At 6 months, the $T$ and 0 groups scored 32 (3.9) and $30(4.0)$ points, respectively $(p<0.001)$, while the RT group scored 32 (4.2) points (not significant when compared with T). There were no significant differences in willingness to act between the groups after 6 months.

Conclusions A practical test including feedback directly after training improved the students' acquisition of practical CPR skills. Reflection did not increase further CPR skills. At 6-month follow-up, no intervention effect was found regarding willingness to make a life-saving effort.
Strengths and limitations of this study

- The best method to teach cardiopulmonary resuscitation (CPR) in school is unknown, therefore we evaluate key concepts in educational science in a cluster randomised trial.

- To study the retention of knowledge and skills after CPR training, assessments were made both directly after intervention and at long-term follow-up.

- The study included students from all socioeconomic areas of two major municipalities in south-east Sweden

- The set-up of the trial did not allow us to explain the cause of differences observed between the intervention groups.

\section{INTRODUCTION}

Sudden unexpected cardiac arrest is one of the most common causes of death in Europe. ${ }^{1}$ Early identification of the cardiac arrest, call to emergency medical service and prompt initiation of bystander cardiopulmonary resuscitation (CPR) are the cornerstones of resuscitation and crucial for survival in out-of-hospital cardiac arrest (OHCA). ${ }^{2}$ Early initiation of CPR at least doubles the survival rate in OHCA. ${ }^{3}{ }^{4}$ Practical CPR training in school, mandatory to all students, would have the potential to significantly increase basic CPR skills on a populational level. Such a situation could potentially increase the lay resuscitation rate. ${ }^{25-8}$

Education in CPR can be delivered in different formats. There is a knowledge gap regarding what is the optimal method of CPR training to acquire CPR skills. ${ }^{2}$ Participants' CPR skills after training are limited and decrease within months after training. ${ }^{29} 10$ 
Learning is a complex process, influenced by several factors. ${ }^{11}{ }^{12}$ Key concepts in educational science are, for example, test, feedback and reflection. Studies show that tests in various formats can increase learning outcomes. ${ }^{13-15}$ Feedback has a powerful influence on performance. ${ }^{16}$ According to the Swedish school curriculum, students are expected to reflect on different situations and events and on their learning. ${ }^{11}$ A core content in CPR training for lay people is practical training; reflection and discussion with the other participants are limited.

The aim of this study was to investigate if two additional interventions, test and reflection, after standard CPR training facilitate learning by comparing 13-year-old students' practical skills and willingness to act. We hypothesised that both the test and the reflection would provide an additional learning session and contribute to improved knowledge. ${ }^{12} 13$

\section{METHODS}

\section{Study population and design}

All council schools with seventh grade students (13 years of age) in two Swedish municipalities (Linköping and Norrköping) were invited to participate in the study. In the framework of this study, the intervention methods were applied in 13 schools. Six schools chose for different reasons not to take part in the study.

Seventh grade students in participating schools were eligible for inclusion. Written study information was sent to the students and their guardians. Oral informed consent was obtained from all study participants. Students were excluded if they declined participation or had a physical handicap that limited their physical performance.

A cluster randomised design was applied, ${ }^{17}$ where each school class was allocated to one of three groups using a randomisation list. The interventions of the groups were based on core concepts in pedagogy: test, feedback and reflection. To evaluate the effect of test including feedback and reflection, the groups were as follows:

- CPR training only $(\mathrm{O})$
- CPR training with a practical skill test including feedback $(\mathrm{T})$

- CPR training with reflection and a practical skill test including feedback (RT).

It was important that the design of the interventions facilitated implementation; the education could fit into one lesson, be given in whole-class and be provided by teachers at the school (less costly, facilitates scheduling). ${ }^{6} 91819$ Outcomes were assessed directly after training and at 6 months. The study was conducted from December 2013 to October 2014.

\section{Standard CPR training applied in all groups}

All intervention groups $(\mathrm{O}, \mathrm{T}$ and $\mathrm{RT})$ received standardised practical CPR training and the participants used an individual training manikin, MiniAnne (manufactured by Laerdal, Stavanger,Norway), during training. The training sessions were conducted in accordance with current European Resuscitation Council guidelines. ${ }^{20}$ Training was performed in a whole-class set-up with 14-29 students in each class. Teachers at the schools, who all were CPR instructors, were responsible for the CPR training. ${ }^{6918}$ They received oral and written information to be updated on the present interventions. CPR training was carried out during a $45-60 \mathrm{~min}$ lesson. The training was either mobile application or digital video disc based, ${ }^{21}$ evenly distributed in the intervention groups (table 1). The teachers served as facilitators of the CPR training sessions as previously described. ${ }^{21}$ After the standardised practical CPR training, the additional interventions, test and reflection, were performed.

\section{Additional intervention with a practical test including feedback}

To compare learning outcomes, the students in groups $\mathrm{T}$ and RT performed a practical test for 3 min directly after the CPR training. Tests can increase learning outcomes, therefore we chose to investigate if the test contributed to the learning session. ${ }^{13-15}$ The test was performed individually as previously described..$^{21}$ In brief, the student was

Table 1 Characteristics of the students

\begin{tabular}{|c|c|c|c|c|c|}
\hline & $\begin{array}{l}\text { CPR only (O) } \\
(n=171)\end{array}$ & $\begin{array}{l}\text { CPR+test and } \\
\text { feedback }(T)(n=224)\end{array}$ & O vs T p value & $\begin{array}{l}\text { CPR+reflection+test } \\
\text { and feedback (RT) } \\
(n=192)\end{array}$ & $\begin{array}{l}\text { T vs } R T \\
p \text { value }\end{array}$ \\
\hline Male & $88(52)$ & $116(52)$ & NS & $79(41)$ & 0.03 \\
\hline $\begin{array}{l}\text { Previous compression } \\
\text { training }\end{array}$ & $49(29)$ & $54(24)$ & NS & $49(26)$ & NS \\
\hline Previous ventilation training & $34(20)$ & $41(18)$ & NS & $39(20)$ & NS \\
\hline App method & $72(42)$ & $113(50)$ & NS & $95(50)$ & NS \\
\hline $\begin{array}{l}\text { Number of schools in which } \\
\text { methods were applied }\end{array}$ & 8 & 7 & & 9 & \\
\hline
\end{tabular}

A total of 587 participants were included in the analyses, distributed in three groups. Values are presented as $\mathrm{n}(\%)$. Differences in proportions between groups were analysed by Pearson's $\chi^{2}$ test.

CPR, cardiopulmonary resuscitation; NS, not significant. 
introduced to an OHCA scenario and asked to perform the correct actions. Optimal performance included $30 \mathrm{~s}$ to check for responsiveness, respiration and call for help, followed by $2.5 \mathrm{~min}$ of CPR. The CPR should include at least five cycles, each consisting of 30 compressions and two ventilations.

The Laerdal PC skill reporting system V.2.4, connected to manikin ResusciAnne, measured the quantitative data, whereas direct observation by the investigator was used to evaluate how well the student checked for responsiveness and respiration and called for help. ${ }^{21}$ All data were recorded directly into a modified version of the Cardiff test, ${ }^{22}$ where a score in each of 12 items resulted in a total score of 12-48 points (see online supplementary file 1 ).

After the test, the investigator gave individual feedback for $2 \mathrm{~min}$. The feedback was partly based on Hattie and Timperley's model, which addresses the following questions: 'where am I going' (the goals), 'how am I going?' (feedback) and 'where to next?' (advice on progress). ${ }^{23}$

\section{Additional intervention with reflection}

After the CPR training, the students in group RT discussed three reflective questions for $15 \mathrm{~min}$. The teacher asked one question at a time. The students discussed and reflected on each question pairwise. The pairs then shared what they had discussed with the whole class. The teacher summarised the answers and asked the next question. In the present study, the aim of the reflection was afterthought. ${ }^{2425}$ Reflections were based on the students' experience, understanding and knowledge and could be enriched with interpretations from a person with more experience. ${ }^{26}$ The three questions were: (1) Imagine yourself in a situation where you see a person suffering from a cardiac arrest. Reflect on which factors influence if you would intervene in a real situation? Remember that your actions may be the difference between life and death; (2) You are alone when a person suffers from a cardiac arrest. According to the guidelines, you should first call 112 and then start CPR, why this order?; (3) Place your hands on the correct compression position on yourself. Reflect on the compression position. Why should the heel of the hand be placed in the centre of the victims' chest? The selection of questions were based on the following: we wanted the students to think about performing a lifesaving intervention so that during the training they would consider how they would act in a real-life situation; in a prestudy, most students failed to call 112; and previous studies have shown that a large proportion of participants apply an incorrect hand position during chest compression. ${ }^{27-29}$

\section{Assessment}

Directly after training and at 6 months, the students in all intervention groups answered a fixed-response questionnaire, which included questions on previous CPR training experience and their willingness to act if faced to an OHCA situation (see online supplementary file 2).

At the 6 month-follow-up, the participants in all intervention groups individually performed a practical CPR test (retention test). The retention test was carried out without prior notice and was conducted in same way as the 'additional intervention with a practical test including feedback'. All measurements were carried out by one investigator (AN), who was blinded to the allocated intervention of the participants.

\section{Study outcome measures}

The primary endpoint was the total score for the modified Cardiff test at 6 months. Total score directly after training, the scores in the individual test categories and self-reported willingness to make a life-saving intervention were secondary endpoints.

\section{Statistical plan and analyses}

Sample size was calculated based on results from a prestudy. ${ }^{28}$ To detect a two-point difference in the mean of the total score of the modified Cardiff test, with an assumed SD of 2.5 points, a significance level of 0.05 and a power of $80 \%$, an effective total sample size of 75 students was needed. ${ }^{30}$ At the first measurement point, we included all available classes (more than calculated) since it is difficult to estimate the size of missing at 6-month follow-up. Cluster randomisation implies that the number of participants is not equal in each training method group due to the different size of the classes. Therefore, a higher number needs to be included to ensure a sufficient number of participants for each method. The intraclass correlation coefficient $(95 \% \mathrm{CI})$ was 0.26 (0.24 to 0.29). ${ }^{1731}$ Based on an average cluster size of 20.2, the design effect caused by the cluster randomisation was calculated to be 5.99. A total of 587 and 549 students performed the first and the second test, respectively. This corresponds to an effective sample size of 98 and 92, respectively, which is above the 75 needed to reach a power of $80 \%$.

To evaluate the effect of test including feedback, group $\mathrm{O}$ was compared with group T. To assess the effect of reflection, group $\mathrm{T}$ was compared with group RT. These comparisons were prespecified and based on separate research questions, and thus no adjustment for multiple testing was performed as this gives no further information about the cause of differences. Data were presented as proportions (per cent) or mean (SD). Differences in proportions were analysed with Pearson's $\chi^{2}$ test. Differences in mean total score between the intervention groups were assessed using unpaired t-test. To account for a potential cluster effect of the school classes, a mixed models linear test was also applied for comparisons of the total score. ${ }^{17}$ By calculating the (individual total score -12$) /($ maximum total score -12$) \times 100$, we obtained a measure of CPR quality in relation to optimal CPR. $\mathrm{p}<0.05$ was considered statistically significant. Analyses were performed using IBM SPSS V.21 and STATA V.13.1.

\section{RESULTS}

Twenty-nine classes involving 587 students were included in the measurements directly after training; 549 (94\%) of 


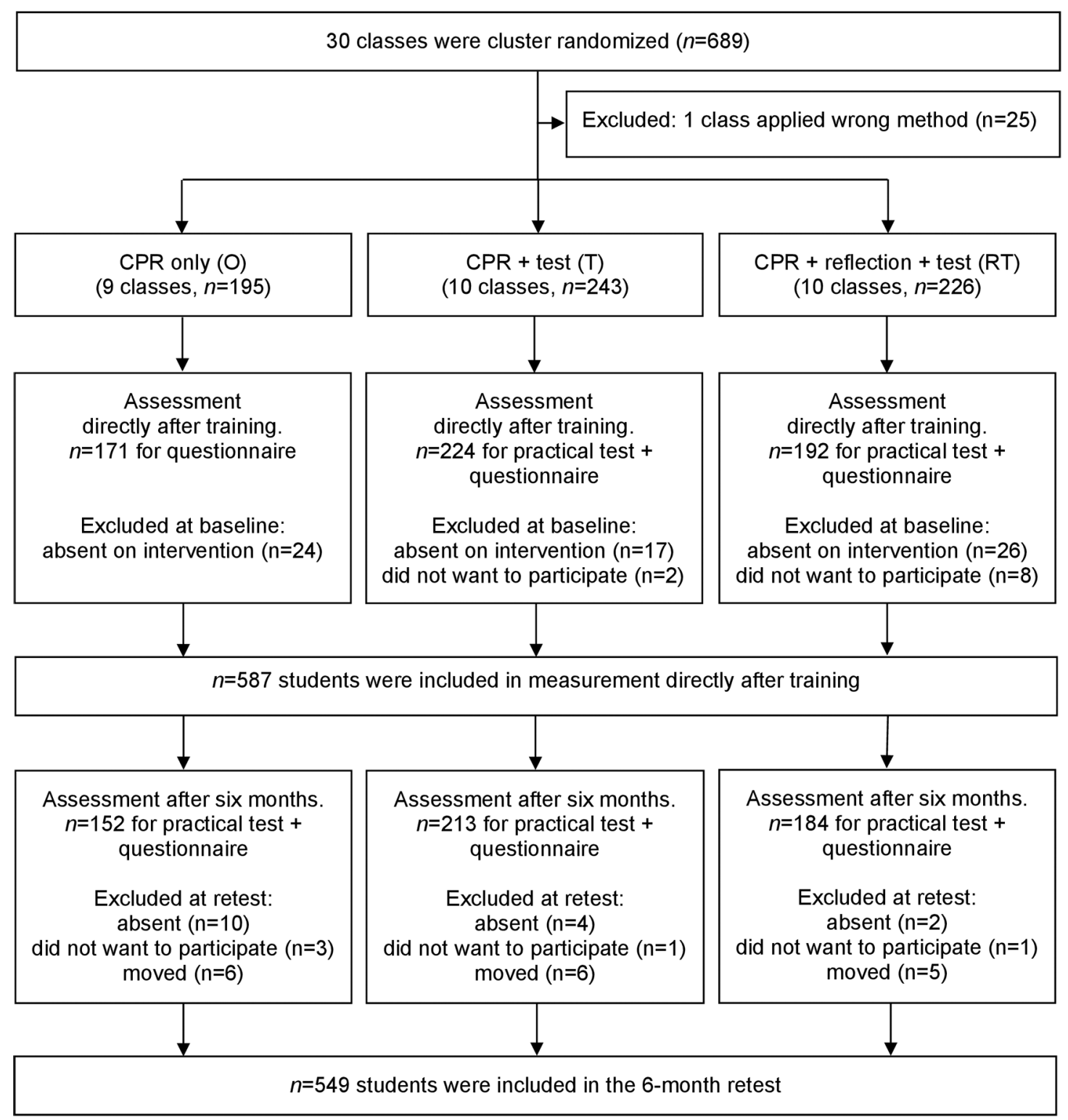

Figure 1 Flow chart on randomisation and inclusion. CPR, cardiopulmonary resuscitation.

these students completed the retest at 6 months (figure 1 ). The students' characteristics are summarised in table 1.

\section{Group 0 versus group $\mathrm{T}$}

At 6 months, group $\mathrm{T}(\mathrm{n}=224)$ performed better than group $\mathrm{O}(\mathrm{n}=171)$ in terms of total score: 32 (3.9) points (56\% of maximum score) versus 30 (4.0) points (50\% of maximum score), $\mathrm{p}<0.001$. For the individual variables, group $\mathrm{T}$ performed significantly better in 8 of 12 variables. Results of the modified Cardiff test are summarised in table 2.

\section{Group T versus group RT}

Directly after training and at the 6-month follow-up, there were no significant differences between group RT $(n=192)$ and group $\mathrm{T}(\mathrm{n}=224)$ with regard to the total score of the modified Cardiff test, calling 112 or hand position during compressions (table 3 ). Directly after CPR training, both groups scored 34 points (61\% of maximum score); and at the 6-month follow-up, group RT scored 31 (4.2) points (53\% of maximum score) and group T scored 32 (3.9) points (56\% of maximum score). Table 3 includes the variables of the practical test that are directly linked to the intervention of reflection as well as the total score of the test. All other variables of the test showed no significant differences between the two groups ( $\mathrm{T}$ vs RT) and have not been included in the table.

\section{Willingness to act}

In the questionnaire, students were asked how confident they felt to act in a cardiac arrest situation after participating in the CPR training session compared with prior to training. A lower proportion of the students in group $\mathrm{O}$ versus group $\mathrm{T}$ stated they felt more confident to act after participating in the training session, when asked directly after training $(73 \%$ vs $88 \%$; $=0.002)$ and at 6 months follow-up ( $73 \%$ vs $82 \%$; $\mathrm{p}=0.025)$. There were 
Table 2 Assessment of CPR skills at the 6 month follow-up

\begin{tabular}{|c|c|c|c|}
\hline & $\begin{array}{l}\text { CPR } \\
\text { only (0) } \\
(n=152)\end{array}$ & $\begin{array}{l}\text { CPR+test } \\
\text { and } \\
\text { feedback } \\
\text { (T) }(n=213)\end{array}$ & p Value \\
\hline \multicolumn{4}{|c|}{ Checks responsiveness by talking } \\
\hline 2: Yes & $23(15)$ & $53(25)$ & 0.024 \\
\hline 1: No & $129(85)$ & $160(75)$ & \\
\hline \multicolumn{4}{|c|}{ Checks responsiveness by shaking } \\
\hline 3: Yes & $25(16)$ & $59(28)$ & 0.012 \\
\hline 2: No & $127(84)$ & $154(72)$ & \\
\hline $\begin{array}{l}\text { 3: Potentially } \\
\text { dangerous }\end{array}$ & 0 & 0 & \\
\hline
\end{tabular}

Open airway-chin lift,

head tilt

\begin{tabular}{|c|c|c|c|}
\hline 5: Perfect & 0 & $1(1)$ & NS \\
\hline 4: Acceptable & $2(1)$ & $6(3)$ & \\
\hline 3: Attempted other & 0 & 0 & \\
\hline 2: Only one element & $8(5)$ & $21(10)$ & \\
\hline 1: No & $142(94)$ & $185(87)$ & \\
\hline \multicolumn{4}{|c|}{ Checks respiration - see, listen, feel } \\
\hline 2: Yes & $49(32)$ & $97(46)$ & 0.011 \\
\hline 1: No & $103(68)$ & $116(54)$ & \\
\hline \multicolumn{4}{|l|}{ Call 112} \\
\hline 2: Yes & $80(53)$ & $171(80)$ & $<0.001$ \\
\hline 1: No & $72(47)$ & $42(20)$ & \\
\hline \multicolumn{4}{|l|}{$\begin{array}{l}\text { Compression/ } \\
\text { ventilation ratio }\end{array}$} \\
\hline $4: 30: 2(28-32: 2)$ & $28(18)$ & $67(32)$ & 0.011 \\
\hline 3: Other ratio & $104(68)$ & $129(61)$ & \\
\hline $\begin{array}{l}\text { 2: Compressions } \\
\text { only }\end{array}$ & $20(13)$ & $17(8)$ & \\
\hline 1: Ventilations only & 0 & 0 & \\
\hline \multicolumn{4}{|c|}{ Hand position during compression } \\
\hline 4: Correct & $8(5)$ & $7(3)$ & NS \\
\hline 3: Other wrong & $59(39)$ & $107(50)$ & \\
\hline 2: Too low & $85(56)$ & $99(46)$ & \\
\hline 1: Not attempted & 0 & 0 & \\
\hline \multicolumn{4}{|l|}{$\begin{array}{l}\text { Average compression } \\
\text { depth }\end{array}$} \\
\hline $6: 50-59 \mathrm{~mm}$ & $55(36)$ & $79(37)$ & 0.030 \\
\hline $5: \geq 60 \mathrm{~mm}$ & 0 & $6(3)$ & \\
\hline 4: $35-49 \mathrm{~mm}$ & $61(40)$ & $97(46)$ & \\
\hline $2: 1-34 \mathrm{~mm}$ & $36(24)$ & $31(15)$ & \\
\hline 1: Not attempted & 0 & 0 & \\
\hline
\end{tabular}

Total compression

counted

\begin{tabular}{llll} 
6: $140-190$ & $52(34)$ & $75(35)$ & NS \\
5: $\geq 191$ & $62(41)$ & $100(47)$ & \\
\hline
\end{tabular}

Continued
Table 2 Continued

\begin{tabular}{|c|c|c|c|}
\hline & $\begin{array}{l}\text { CPR } \\
\text { only (0) } \\
(n=152)\end{array}$ & $\begin{array}{l}\text { CPR+test } \\
\text { and } \\
\text { feedback } \\
(T)(n=213)\end{array}$ & p Value \\
\hline 4: 121-139 & $11(7)$ & $19(9)$ & \\
\hline 3: $81-120$ & $21(14)$ & $14(7)$ & \\
\hline $2: 1-80$ & $6(4)$ & $5(2)$ & \\
\hline 1: Not attempted & 0 & 0 & \\
\hline \multicolumn{4}{|l|}{$\begin{array}{l}\text { Average ventilation } \\
\text { volume }\end{array}$} \\
\hline 5: 500-600 mL & $5(3)$ & 7 (3) & $<0.001$ \\
\hline 4: $1-499 \mathrm{~mL}$ & $11(7)$ & $21(10)$ & \\
\hline $3: \geq 601 \mathrm{~mL}$ & $27(18)$ & $91(43)$ & \\
\hline 2: $0 \mathrm{~mL}$ & $87(57)$ & $77(36)$ & \\
\hline 1: Not attempted & $22(14)$ & $17(8)$ & \\
\hline \multicolumn{4}{|l|}{$\begin{array}{l}\text { Total ventilation } \\
\text { counted }\end{array}$} \\
\hline 5: 8-12 & $15(10)$ & 34 (16) & $<0.001$ \\
\hline $4: 1-7$ & $13(9)$ & $44(21)$ & \\
\hline $3: \geq 13$ & $15(10)$ & 41 (19) & \\
\hline 2: 0 & $87(57)$ & 77 (36) & \\
\hline 1: Not attempted & $22(14)$ & $17(8)$ & \\
\hline \multicolumn{4}{|l|}{ Total hands-off time } \\
\hline 4: $0-60 \mathrm{~s}$ & $55(36)$ & $62(29)$ & 0.024 \\
\hline 3: $61-90 \mathrm{~s}$ & $62(41)$ & $120(56)$ & \\
\hline $2: 91-135 \mathrm{~s}$ & $33(22)$ & $30(14)$ & \\
\hline 1: 136-180s & $2(1)$ & $1(1)$ & \\
\hline Total score & $30(4.0)$ & 32 (3.9) & $<0.001^{\star} \dagger$ \\
\hline
\end{tabular}

Results are presented as $\mathrm{n}(\%)$ or mean (SD). Differences in proportions between groups were analysed by Pearson's $\chi^{2}$ test. Differences in total score between intervention groups were analysed by mixed models linear test ${ }^{\star}$ and unpaired t-test $\dagger$. $p$ Values $<0.05$ were considered statistically significant. The table lists the variable's best option at the top. All numbers are rounded to the nearest whole number. CPR, cardiopulmonary resuscitation; NS, not significant.

also differences in how the students considered that they had enough knowledge to do chest compressions, $60 \%$ $(\mathrm{O})$ versus $81 \%(\mathrm{~T}, \mathrm{p}<0.001)$, and to do rescue breathing, $57 \%$ vs $75 \%(\mathrm{p}<0.001)$. At 6 months, $84 \%(\mathrm{O})$ versus $91 \%$ ( $\mathrm{T}$, not significant) considered they had enough knowledge to do chest compressions and $59 \%(\mathrm{O})$ versus $74 \%$ ( $\mathrm{T}, \mathrm{p}=0.007)$ to do rescue breathing. There were no significant differences between group $\mathrm{T}$ and group RT regarding confidence about acting or self-rated knowledge either after training or at 6 months.

Directly after training, most students responded that they would do both compressions and ventilations if a friend suffered OHCA; 72\% (O), 80\% (T, p=NS when comparing $\mathrm{O}$ and $\mathrm{T}$ ) and $81 \%$ (RT, table 3 ). If a stranger suffered OHCA, there was a significant difference between 


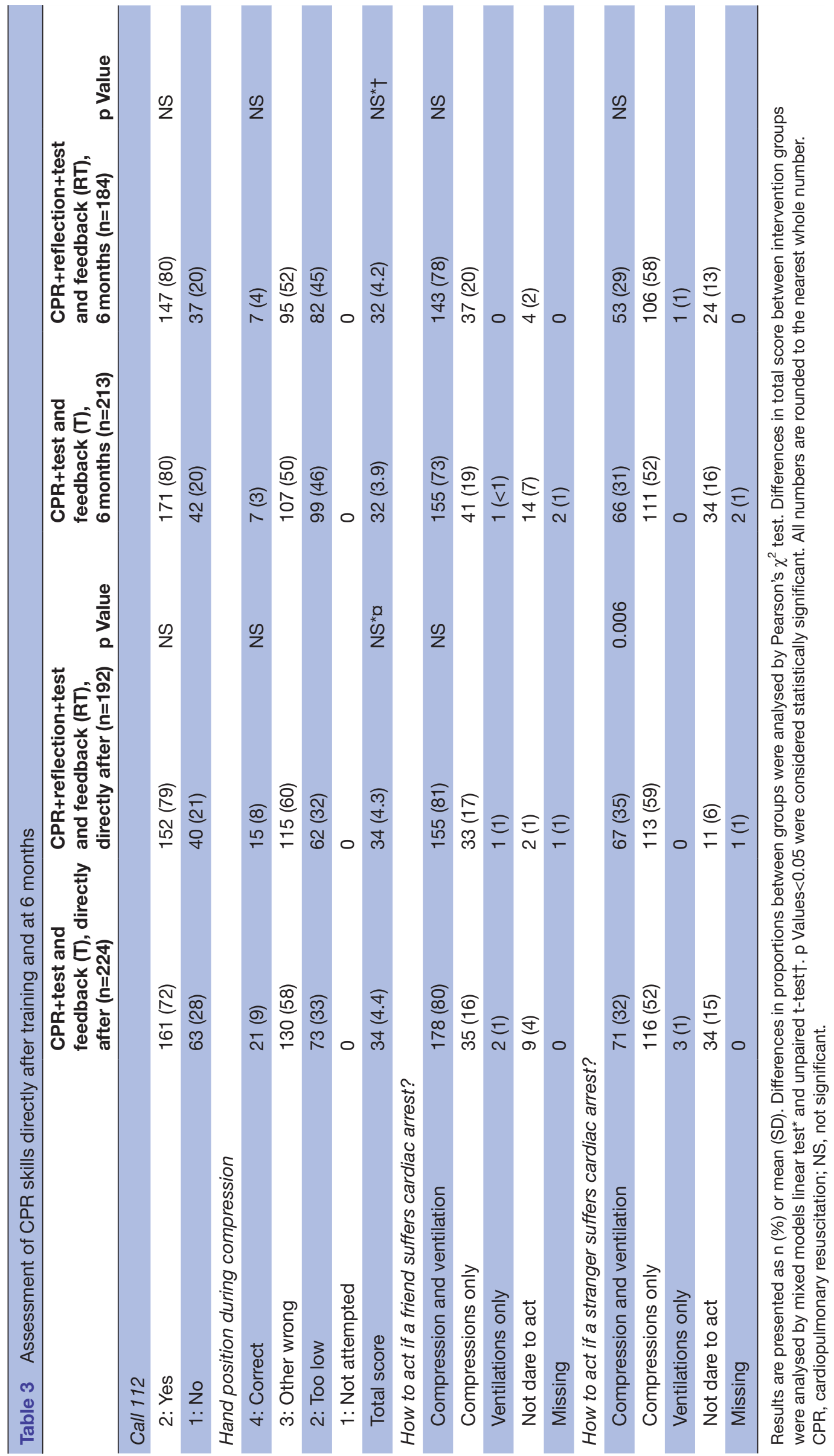

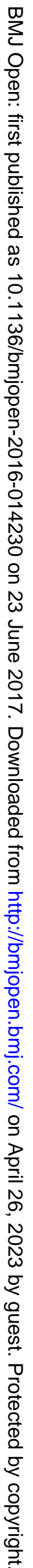


group $\mathrm{T}$ and group RT in how the students would act, with a more positive attitude in group RT (table 3) but there was no significant difference between groups $\mathrm{O}$ and $\mathrm{T}(27 \%$ and $32 \%$ would do both compressions and ventilations).

At 6-month follow-up, there were no significant differences between the three intervention groups with regard to how they would act in OHCA situations; $76 \%(\mathrm{O})$, $73 \%$ (T) and $78 \%$ (RT) would do both compressions and ventilations if a friend suffered a cardiac arrest. Only $31 \%(\mathrm{O}$ and $\mathrm{T}$ ) versus $29 \%$ (RT) were prepared to do compressions and ventilations if a stranger suffered a cardiac arrest.

\section{DISCUSSION}

The main findings of the present study are threefold. First, adding a practical test with feedback after CPR training resulted in significantly improved practical skills at the 6-month follow-up. Second, reflection added to CPR training did not influence the practical skills. Third, adding a practical test with feedback or reflection to CPR training did not affect long-term willingness to make a life-saving effort. The study was performed in schools of diverse socioeconomic background and each intervention was applied in seven to nine different schools, strengthening the generalisability of our findings.

The group with a practical test including feedback $(\mathrm{T})$ added after CPR training showed superior practical skills at 6 months compared with the group with CPR training only $(\mathrm{O})$. However, the clinical relevance of the two-point difference in the total score for the modified Cardiff test is unclear. We discuss possible reasons for the outcome linked to learning theories. The result may be due to a further $3 \mathrm{~min}$ of hands-on training under the supervision of the investigator or due to the individual feedback the students received after the test. ${ }^{14}$ Previous studies indicate that testing can increase learning outcomes compared with an equal amount of time spent on training. ${ }^{1315}$ The test was not only a tool to assess skills but also an opportunity to give the students' feedback. ${ }^{32}$ The feedback aimed to reduce discrepancies between present understanding and the goal. ${ }^{23} \mathrm{Li}$ et $a l^{32}$ indicate that a pretest and feedback can inspire learners to develop strategies to minimise their dependence on feedback from the instructors, which improve skill acquisition and skill retention. At feedback, the question 'where to next?' was assumed to be the most important question, while praise for a task seems to be less effective. ${ }^{23} 33$ A limitation is that the feedback to the students was given when the training was completed. In a prestudy, some students indicated that feedback helped to strengthen their self-esteem. ${ }^{28}$ According to Bandura, ${ }^{34}$ and social cognitive theory, an individual's self-efficacy may affect a person's performance. Self-efficacy is about a person's confidence in their own ability (not actual ability) in a given situation. Self-efficacy can be affected by verbal persuasion. ${ }^{35}$ Further studies are needed to elucidate whether the results were caused by the additional training during supervision or by the feedback given to the students. Use of a feedback device is another form of feedback that may improve skill acquisition. ${ }^{2}$ A feedback device was not tested in this study.

According to the Swedish school curriculum, knowledge 'can be expressed in a variety of forms, as facts, understanding, skills, familiarity and accumulated experience'. ${ }^{11}$ Reflection and practical training are two teaching methods that can contribute to understanding, skills and familiarity. There are many definitions of reflection, which implies that there are many different models. ${ }^{25}{ }^{26} \mathrm{In}$ this study, the aim of the reflection was afterthought. ${ }^{2425}$ Adding reflection to CPR training did not influence the students' practical skills. In particular, reflection did not improve calling 112 and hand positioning during compressions, despite both being included in the reflective questions. Directly after training, a higher proportion of students in the reflection group were willing to intervene if a stranger suffered a cardiac arrest, but this difference could not be observed at 6 months. This result might, at least in part, be explained by the content and the framing of the reflective questions. The first question, concerning how the students would act in an OHCA situation, is based on ethical considerations, which may provoke emotions and empathy in students. ${ }^{36}$ These emotions might have affected the participants close to the training but not in the long term. Questions two (calling 112 ) and three (hand positioning during compressions) were a cognitive complement to the practical training. Thus, the students might have discussed and answered these questions as knowledge questions, rather than questions to reflect on. Perhaps the outcome would have been different if these reflective questions had been asked when the action was practised, so-called reflection on action. ${ }^{26}$ Mann et $a l^{25}$ stated that there is no evidence to support or refute the assumption that reflection will enhance competence. Ixer ${ }^{37}$ stated that we do not know enough about reflection or how it can enhance learning. Further research is needed to clarify whether and how reflection can be used as a successful teaching tool in CPR training.

Practical training increases willingness to intervene in a real situation. ${ }^{238}$ At the 6-month follow-up, the three intervention groups did not differ with regard to willingness to make a life-saving effort. Regardless of the intervention method, we found, in accordance with previous studies, a huge difference in willingness to intervene in an OHCA situation involving a friend compared with a situation involving a stranger. ${ }^{38-41}$

\section{Study limitations}

First, we cannot exclude that students who performed a test directly after training were more familiar with the test manikin at the retention test at 6 months. However, during the test, the participants do not take part of the technical feedback received from the full-body Resusci Anne and should thus not have any advantage. The same design has also been used in other studies. ${ }^{1427}$ 
Second, the characteristics of the CPR instructor may affect the learning process of the students. We have no data on the individual instructors regarding their previous experience of and attitude towards CPR training. However, they were all regular teachers of the participating school classes and prior to the study they all received standardised information on current CPR guidelines and detailed instructions on how to perform their allocated CPR training interventions.

Third, the intervention was carried out in two major municipalities. We do not know how applicable the results are for other locations, but a strength of the present study is that schools from all socioeconomic areas were included.

\section{CONCLUSIONS}

This study contributes to knowledge on the efficiency of two additional CPR training interventions. A practical test with feedback in connection with CPR training is an efficient strategy to increase learning outcome, both practical skills and self-rated knowledge, when teaching seventh grade students. Further studies are needed to find alternative methods for testing and feedback, and to elucidate how feedback works most effectively in the CPR learning process. Reflective questions, in the format applied in this study, did not increase the participants' practical CPR skills. Importantly, regardless of the intervention applied, most students indicated they would intervene in an OHCA situation.

\section{Author affiliations}

${ }^{1}$ Department of Medical and Health Sciences, Linköping University, Linköping,

\section{Sweden}

${ }^{2}$ Department of Clinical Science, Intervention and Technology, Karolinska Institute, Stockholm, Sweden

${ }^{3}$ Department of Behavioural Sciences and Learning, Linköping University, Linköping, Sweden

${ }^{4}$ The Prehospital Research Centre of Western Sweden, Borås University, Borås, Sweden

${ }^{5}$ Department of Medicine, Karolinska Institute, Stockholm, Sweden

Correction notice This paper has been amended since it was published Online First. Owing to a scripting error, some of the publisher names in the references were replaced with 'BMJ Publishing Group'. This only affected the full text version, not the PDF. We have since corrected these errors and the correct publishers have been inserted into the references.

Acknowledgements The authors would like to thank all the students and teachers who participated in the study.

Contributors AN contributed to the study design, developed the modified Cardiff test and the questionnaire, conducted all measurements, analysed results and wrote the initial draft of the manuscript. LS and JH contributed to the study design, developed the modified Cardiff test and revised the manuscript. HH and SKS contributed to the study design and revised the manuscript. LN contributed to the study design, developed the modified Cardiff test and the questionnaire, analysed results and revision of the manuscript.

Funding The study was supported by the Foundation for Cardiopulmonary Resuscitation in Sweden, Swedish Resuscitation Council, Swedish Heart-Lung Foundation (award number 20130629) and the County Council of Östergötland. The funders had no role in study design, data analysis, decision to publish or preparation of manuscript.

Competing interests None declared.
Patient consent Detail has been removed from this case description/these case descriptions to ensure anonymity. The editors and reviewers have seen the detailed information available and are satisfied that the information backs up the case the authors are making.

Ethics approval The Regional Ethical Review Board of Linkping, Sweden (2013/35831).

Provenance and peer review Not commissioned; externally peer reviewed. Data sharing statement № additional unpublished data available.

Open Access This is an Open Access article distributed in accordance with the Creative Commons Attribution Non Commercial (CC BY-NC 4.0) license, which permits others to distribute, remix, adapt, build upon this work non-commercially, and license their derivative works on different terms, provided the original work is properly cited and the use is non-commercial. See: http://creativecommons.org/ licenses/by-nc/4.0/

(C) Article author(s) (or their employer(s) unless otherwise stated in the text of the article) 2017. All rights reserved. No commercial use is permitted unless otherwise expressly granted.

\section{REFERENCES}

1. Perkins GD, Handley AJ, Koster RW, et al. European Resuscitation Council Guidelines for Resuscitation 2015: section 2. Adult basic life support and automated external defibrillation. Resuscitation 2015;95:81-99.

2. Greif R, Lockey AS, Conaghan P, et al. European Resuscitation Council Guidelines for Resuscitation 2015: section 10. Education and implementation of resuscitation. Resuscitation 2015;95:288-301.

3. Hasselqvist-Ax I, Riva G, Herlitz J, et al. Early cardiopulmonary resuscitation in out-of-hospital cardiac arrest. N Engl J Med 2015;372:2307-15.

4. Holmberg M, Holmberg S, Herlitz J. Effect of bystander cardiopulmonary resuscitation in out-of-hospital cardiac arrest patients in Sweden. Resuscitation 2000;47:59-70.

5. Cave DM, Aufderheide TP, Beeson J, et al. Importance and implementation of training in cardiopulmonary resuscitation and automated external defibrillation in schools. Circulation 2011;123:691-706.

6. Bohn A, Van Aken H, Lukas RP, et al. Schoolchildren as lifesavers in Europe - training in cardiopulmonary resuscitation for children. Best Pract Res Clin Anaesthesiol 2013;27:387-96.

7. Böttiger BW, Van Aken H. Kids save lives--training school children in cardiopulmonary resuscitation worldwide is now endorsed by the World Health Organization (WHO). Resuscitation 2015;94:A5-7.

8. Wissenberg M, Lippert FK, Folke F, et al. Association of national initiatives to improve cardiac arrest management with rates of bystander intervention and patient survival after out-of-hospital cardiac arrest. JAMA 2013;310:1377-84.

9. Plant N, Taylor K. How best to teach CPR to schoolchildren: a systematic review. Resuscitation 2013;84:415-21.

10. Abelairas-Gómez C, Rodríguez-Núñez A, Casillas-Cabana M, et al. Schoolchildren as life savers: at what age do they become strong enough? Resuscitation 2014;85:814-9.

11. Swedish National Agency for Education. Swedish curriculum for the compulsory school, preschool class and the recreation centre 2011. http://www.skolverket.se/publikationer?id=2687. (accessed $16 \mathrm{Mar}$ 2016).

12. Kolb DA. Experimental learning: experience as the source of learning and development. Englewood Cliffs, NJ: Prentice Hall, 1984.

13. Kromann CB, Jensen ML, Ringsted C. The effect of testing on skills learning. Med Educ 2009;43:21-7.

14. de Vries W, Turner NM, Monsieurs KG, et al. Comparison of instructor-led automated external defibrillation training and three alternative DVD-based training methods. Resuscitation 2010;81:1004-9.

15. Roediger HL, Karpicke JD. The power of testing memory: basic research and implications for educational practice. Perspect Psychol Sci 2006;1:181-210.

16. Hattie J. Visible learning: a synthesis of over 800 meta-analyses relating to achievement. New York: Routledge, 2009.

17. Donner A, Klar N. Design and analysis of cluster randomization trials in health research. London: Arnold Publishing, 2000.

18. Lukas RP, Van Aken H, Mölhoff T, et al. Kids save lives: a six-year longitudinal study of schoolchildren learning cardiopulmonary resuscitation: who should do the teaching and will the effects last? Resuscitation 2016;101:35-40. 
19. Colquhoun M. Learning CPR at school--everyone should do it. Resuscitation 2012;83:543-4.

20. Koster RW, Baubin MA, Bossaert LL, et al. European Resuscitation Council Guidelines for Resuscitation 2010 Section 2. Adult basic life support and use of automated external defibrillators. Resuscitation 2010;81:1277-92.

21. Nord A, Svensson L, Hult $\mathrm{H}$, et al. Effect of mobile applicationbased versus DVD-based CPR training on students' practical CPR skills and willingness to act: a cluster randomised study. BMJ Open 2016;6:e010717.

22. Whitfield RH, Newcombe RG, Woollard M. Reliability of the cardiff test of basic life support and automated external defibrillation version 3.1. Resuscitation 2003;59:291-314.

23. Hattie J, Timperley H. The power of feedback. Rev Educ Res 2007:77:81-112.

24. Higgins D. Why reflect? recognising the link between learning and reflection. Reflective Practice 2011;12:583-4.

25. Mann K, Gordon J, MacLeod A. Reflection and reflective practice in health professions education: a systematic review. Adv Health Sci Educ Theory Pract 2009;14:595-621.

26. Hébert $\mathrm{C}$. Knowing and/or experiencing: a critical examination of the reflective models of John Dewey and Donald Schön. Reflective Practice 2015:16:361-71.

27. Nielsen AM, Isbye DL, Lippert F, et al. Distributing personal resuscitation manikins in an untrained population: how well are basic life support skills acquired? Emerg Med J 2012;29:587-91.

28. Nord A. CPR training in 7th grade. Instructor-led or DVD-based, which teaching method is most effective? master: Linköpings University, 2013:03. http://liu.diva-portal.org/smash/record.jsf?pid= diva2\%3A812920\&dswid=5577. (accessed 10 Apr 2016).

29. Iserbyt $P, B y r a M$. The design of instructional tools affects secondary school students' learning of cardiopulmonary resuscitation (CPR) in reciprocal peer learning: a randomized controlled trial. Resuscitation 2013;84:1591-5.
30. Chow S, Shao J, Wang H. Sample size calculations in clinical research. Chapman \& Hall/CRC, Boca Raton 2008.

31. Killip S, Mahfoud Z, Pearce K. What is an intracluster correlation coefficient? Crucial concepts for primary care researchers. Ann Fam Med 2004;2:204-8.

32. Li Q, Zhou RH, Liu J, et al. Pre-training evaluation and feedback improved skills retention of basic life support in medical students. Resuscitation 2013;84:1274-8.

33. Wollenschläger $\mathrm{M}$, Hattie $\mathrm{J}$, Machts $\mathrm{N}$, et al. What makes rubrics effective in teacher-feedback? Transparency of learning goals is not enough. Contemp Educ Psychol 2016;44-45:1-11.

34. Bandura A. Social cognitive theory: an agentic perspective. Annu Rev Psychol 2001;52:1-26.

35. Bandura A. Self-efficacy: the exercise of control. New York, NY: Freeman, 1997.

36. Immordino-Yang MH, Damasio A. We feel, therefore we learn: the relevance of affective and social neuroscience to education. Mind, Brain, and Education 2007;1:3-10.

37. Ixer G. There's no such thing as reflection. Br J Soc Work 1999;29:513-27.

38. Cho GC, Sohn YD, Kang KH, et al. The effect of basic life support education on laypersons' willingness in performing bystander hands only cardiopulmonary resuscitation. Resuscitation 2010;81:691-4.

39. Kanstad BK, Nilsen SA, Fredriksen K. CPR knowledge and attitude to performing bystander CPR among secondary school students in Norway. Resuscitation 2011;82:1053-9.

40. Omi W, Taniguchi T, Kaburaki T, et al. The attitudes of Japanese high school students toward cardiopulmonary resuscitation. Resuscitation 2008;78:340-5

41. Baldi E, Bertaia D, Savastano S. Mouth-to-mouth: an obstacle to cardiopulmonary resuscitation for lay-rescuers. Resuscitation 2014;85:e195-e196. 